\title{
CARNAVAL DO ANO 2000 E OS ENREDOS HISTÓRICOS
}

Madson Luís Gomes de Oliveira (UFRJ)

Levantamento e análise dos enredos históricos em 2000, a partir da leitura dos Históricos e das Justificativas descritos nos cadernos Abre-Alas, redigidos pelas próprias agremiações carnavalescas.

ENREDO; ESCOLAS DE SAMBA; CARNAVAL.

OLIVEIRA, Madson Luís Gomes de. Carnaval do ano 2000 e os enredos históricos. Textos escolhidos de cultura e arte populares, Rio de Janeiro, v.10, n.2, p. 169-180, nov. 2013. 


\section{CARNIVAL OF THE YEAR 2000 AND THE HISTORICAL PLOTS}

Madson Luís Gomes de Oliveira (UFRJ)

Survey and analysis of historical plots in 2000, from the reading of the Records and Justifications found in the Abre-Alas summary, written by the carnival associations themselves.

PLOT; SAMBA SCHOOLS; CARNAVAL.

OLIVEIRA, Madson Luís Gomes de. Carnaval do ano 2000 e os enredos históricos. Textos escolhidos de cultura e arte populares, Rio de Janeiro, v.10, n.2, p. 169-180, nov. 2013. 


\section{INTRODUÇÃO ${ }^{1}$}

Conforme observado na tese de doutorado intitulada Imaginários da criação: o tempo e o espaço dos souvenirs carnavalescos (OLIVEIRA, 2010), o carnaval carioca e os desfiles de escolas de samba devem ser entendidos concomitantemente como produto e produtor de significações oriundas do turismo, enquanto prática social que produz bens simbólicos. ${ }^{2}$ Uma grande quantidade de pessoas e profissionais se envolve anualmente com a produção dos desfiles das escolas de samba, durante vários meses do ano. Esse dado complementa nosso interesse pelo assunto, pois, além do entendimento da sociedade por meio dos bens simbólicos, nos voltamos também para o processo do envolvimento econômico de profissionais liberais como figurinistas, cenógrafos, costureiras, aderecistas, etc.

Os desfiles das escolas de samba carioca configuram tema muito extenso e passível de vários estudos, com objetivos diversificados. Para iniciar essa pesquisa, fizemos um recorte temporal como foco principal sobre nosso objeto de estudo: os enredos históricos. A escolha do período para o levantamento sobre os enredos históricos pautou-se, especialmente, pelo fechamento de um ciclo histórico (século e milênio), no ano 2000. Assim, poderemos futuramente fazer uma análise do último ano do século $\mathrm{XX}$, como uma espécie de radiografia dos temas desfilados. Por enquanto, apresentamos, parcialmente, o início do levantamento das pesquisas, pois a investigação encontra-se, ainda, em andamento.

A principal fonte pesquisada para o levantamento dos enredos históricos foi os cadernos de Abre-Alas produzidos pela Liga Independente das Escolas de Samba do Rio de Janeiro - Liesa, arquivados e fornecidos pelo Centro de Memória do Carnaval, mantido pela entidade.

Os cadernos Abre-Alas são roteiros explicativos sobre os desfiles das escolas de samba do Grupo Especial, organizados pela Liesa a partir dos dados fornecidos pelas próprias escolas de samba e entregues aos membros da comissão julgadora dos desfiles, no domingo e na segunda-feira de carnaval. Araújo (2010, p. 153) informa o conteúdo dos cadernos:

São publicados dois volumes por ano, um para cada dia de desfile. A forma-padrão de apresentação inclui: 1- Ficha Técnica do Enredo (onde constam autores e bibliografia); 2 - Histórico do Enredo; 3 Justificativa do Enredo; 4 - Roteiro de Desfile; 5 - Ficha Técnica das Alegorias; Ficha Técnica das Fantasias; 7 - Ficha Técnica do Sambaenredo; 8 - Ficha Técnica da Bateria; 9 - Ficha Técnica da Harmonia; 10 - Ficha Técnica da Evolução; 11 - Ficha Técnica do Conjun- 
to; 12 - Ficha Técnica da Comissão de Frente; 13 - Ficha Técnica do Mestre-Sala e Porta-Bandeira.

Dessa maneira, as informações são padronizadas para todas as escolas de samba, explicitando as fontes de pesquisas que cada carnavalesco (ou equipe) utilizou para o desenvolvimento do enredo, bem como justificando suas escolhas e as soluções encontradas.

Cabe lembrar que, para o desenvolvimento de um desfile de escola de samba, há um fio condutor, uma narrativa, um roteiro que conta uma história, conforme Magalhães (1997, p. 26):

Uma das características das Escolas de Samba é contar uma história que a cada ano tem de ser diferente. Ter um tema e contar a história dará origem a todas as outras etapas subsequentes, até culminar com o desfile de carnaval. O enredo, portanto, é o fio condutor da letra e da melodia do samba, e vai orientar a criação e execução dos trajes, o desenho dos carros alegóricos, a escolha das cores e dos efeitos coreográficos, assim por diante.

Mesmo havendo um enredo que norteia o trabalho nos desfiles das escolas de samba, vários são os motivos que podem gerar o mote da narrativa. Seja para atender à proposta de patrocínio, data comemorativa ou outras situações, as agremiações carnavalescas justificam suas escolhas estéticas a partir de uma pesquisa, por exemplo.

Ao longo do tempo, percebemos que os enredos formam alguns grupos temáticos que alguns interessados no assunto tentaram classificar. Segundo Magalhães (1997, p. 26), “Há diversos enfoques para os assuntos escolhidos, pode ser histórico, jocoso, crítico, descritivo, associativo. O mais importante é que tenha uma leitura para o entendimento popular". Farias (2007, p. 48), no entanto, adverte que alguns enredos podem integrar-se em mais de uma categoria:

Os temas dos enredos são muito variados. Podemos distinguir pelo menos os seguintes tipos: histórico, literário, folclórico, homenagem a personalidade/biográfico, metalinguístico, geográfico, de crítica social, de humor, abstrato ou conceitual, sobre objetos, esportivo, de temática infantil, de temática afro-brasileira, de temática indígena e de patrocínio. Sendo que vários enredos podem se inserir em mais de uma categoria.

Observe-se que a temática histórica aparece em primeiro lugar em ambas as citações. Mesmo percebendo que, em alguns casos, as escolas de samba utilizam mais de uma abordagem nos enredos de um desfile, aqueles de cunho histórico costumam ter destaque. 
Como não há metodologia única para a criação dos enredos carnavalescos, sugerimos para nossa análise uma síntese dos temas elencados pelos dois autores anteriormente citados.

Assim, essa pesquisa se debruça sobre as informações descritas no histórico e/ou na justificativa de cada enredo, ou seja, utilizamos as palavras das próprias escolas de samba.

A leitura dos manuais seguiu, cronologicamente, os desfiles apresentados no ano 2000, 14 ao todo, sete em cada noite.

\section{OS ENREDOS NO ANO 2000}

Para melhor compreensão do leitor, preferimos apresentar os enredos pesquisados em dois blocos, um para cada noite, cronologicamente arranjados e na sequência apresentada pelos cadernos de Abre-Alas. Para tanto, organizamos os dados pesquisados em duas tabelas a fim de padronizar as informações, distribuídas em cinco colunas: a primeira informa o dia do desfile ( $D=$ domingo ou $\mathrm{S}$ = segunda) e a sequência do desfile; a segunda revela o nome da escola de samba; a terceira refere o carnavalesco (individual, dupla ou comissão) da agremiação; a quarta informa o título do enredo; e, finalmente, a última classifica o enredo.

Os diferentes enredos foram classificados seguindo síntese proposta a partir da junção dos dois modelos citados apresentados por Magalhães (1997) e Farias (2007). Assim, classificamos os enredos como: H - Histórico; L - Localidade; A - Associação; B - Biográfico; e I - Imaginário, e só analisamos os de cunho histórico. Entendemos por histórico aquele enredo que apresenta em sua justificativa os fatos históricos, além de respeitar datas e personalidades referentes ao tema tratado. Os enredos classificados como localidade são aqueles que claramente homenageiam uma cidade ou região, geograficamente mapeada. Os enredos associativos são aqueles que podem até utilizar uma pesquisa histórica ou visitar uma localidade, mas não se prendem aos fatos ocorridos para criar associação entre a referência e as partes do enredo. Os de cunho biográfico são os enredos que prestam homenagem a personalidades, mas levando em consideração os momentos mais marcantes de sua vida, incluindo os dados pessoais. Os enredos de caráter imaginário são aqueles que se apoiam em fatos não necessariamente reais, como lendas, contos, histórias orais, sonhos e fatos de difícil comprovação. 
Vale a pena destacar que, especificamente, em 2000, as escolas de samba foram incentivadas a ressaltar os 500 anos de descobrimento do Brasil, levando em conta que a historiografia oficial tem em 1500 a data de seu descobrimento. Ademais, 2000 foi o último do século XX e do segundo milênio, representando um momento de reflexão para vários setores da sociedade.

O primeiro grupo de enredos refere-se à noite de domingo do Carnaval de 2000, conforme Tabela 1.

\begin{tabular}{|c|c|c|c|c|}
\hline \multicolumn{5}{|c|}{ DOMINGO } \\
\hline Dia & $\begin{array}{l}\text { Escola de } \\
\text { Samba }\end{array}$ & Carnavalesco & Enredo & $\mathbf{T}$ \\
\hline $\mathrm{D} 1$ & Porto da Pedra & Jaime Cezário & $\begin{array}{l}\text { Ordem, progresso, amor e folia no mi- } \\
\text { lênio de fantasia! }\end{array}$ & A \\
\hline $\mathrm{D} 2$ & Grande Rio & Max Lopes & Carnaval à vista & $\mathrm{H}$ \\
\hline D3 & Vila Isabel & Oswaldo Jardim & Eu sou índio. Eu também sou imortal & $\mathrm{A}$ \\
\hline D4 & Caprichosos & Etevaldo Brandão & Brasil, teu Espírito é Santo! & A \\
\hline D5 & Tradição & Orlando Júnior & Liberdade! Sou negro, raça e Tradição! & $\mathrm{H}$ \\
\hline D6 & $\begin{array}{l}\text { Moc i d a d e } \\
\text { Independente }\end{array}$ & Renato Lage & $\begin{array}{l}\text { Verde, amarelo, azul-anil, colorem o } \\
\text { Brasil no ano } 2000\end{array}$ & $A / I$ \\
\hline D7 & Portela & José Félix & $\begin{array}{l}\text { Trabalhadores do Brasil: a época de Ge- } \\
\text { túlio Vargas }\end{array}$ & $\mathrm{H}$ \\
\hline
\end{tabular}

O primeiro enredo a ser analisado é o do GRES Porto da Pedra, intitulado “Ordem, progresso, amor e folia no milênio de fantasia!" e considerado associativo, pois o carnavalesco busca inspiração na formação do imaginário sobre as palavras ordem e progresso.

A segunda escola a desfilar no Grupo Especial do carnaval carioca foi o GRES Grande Rio, cujo enredo pautou-se nas datas históricas que serviram para contribuir com a festa carnavalesca ao longo dos 500 anos, conforme explica o próprio carnavalesco, Max Lopes, na justificativa do enredo:

A simples leitura do texto, dá uma exata noção da essência do original enredo, todo ele voltado para a alegria, reproduzindo, com belíssimas caracterizações, os diversos períodos dos 500 anos de carnaval, festejados no país, desde a época da sua colonização até a época contemporânea (CENTRO DE MEMóRIA, v.1, 2000, p. 70).

A Vila Isabel utilizou como tema do desfile para o Carnaval de 2000 uma espécie de louvor aos índios, como irmãos mais velhos da tríade étnica que compôs a mistura brasileira, juntamente com os portugueses e os negros. Dada a maneira como o carnavalesco Oswaldo Jardim desenvolveu esse enredo, ele foi classificado como associativo, devido à relação que estabelece entre o indígena e a semente que cultiva a vida. 
Etevaldo Brandão, carnavalesco do GRES Caprichosos de Pilares, em 2000, desenvolveu enredo que, mesmo fazendo um recorte histórico (entre 1961 e 1992), focou em alguns episódios, sem obrigatoriedade da sequência de datas e fatos históricos. Assim, optamos por classificar o enredo como de cunho associativo, pois o carnavalesco não explicita datas, mas coloca em relevo os movimentos musicais (como Bossa Nova, Jovem Guarda e Hippie) recortados no período.

A Tradição levou para seu desfile, em 2000, o enredo "Liberdade! Sou negro, raça e Tradição!", desenvolvido pelo carnavalesco Orlando Júnior e que entendemos como histórico, pois a proposta pauta-se na história do negro brasileiro, ao longo dos tempos.

A Escola de Samba que traz seu nome, focalizará também a importância do negro nesses 500 anos que iremos celebrar, como defensor da sua própria dignidade, através de manifestações artísticas e culturais de uma época. Tais manifestações, por pertencerem ao povo, não foram devidamente exploradas pela História do Rio de Janeiro (CENTRO DE MEMóRIA, v.1, 2000, p. 176).

O enredo "Verde, amarelo, azul-anil, colorem o Brasil no ano 2000" foi desenvolvido por Renato Lage, para o carnaval da Mocidade Independente de Padre Miguel, em 2000. A temática desse enredo não trata de nenhuma localidade específica, nenhuma personalidade ou fato histórico, ficando, portanto, fora de nosso escopo para análise, pois o carnavalesco se inspira, ao mesmo tempo, numa nave imaginária que traz do espaço sideral "aborígenes do futuro", estabelecendo também associações entre as cores de nossa bandeira e as paisagens, os mistérios e as lendas brasileiras.

A Portela levou para a avenida o enredo "Trabalhadores do Brasil-A época de Getúlio Vargas", desenvolvido pelo carnavalesco José Félix. Mesmo tratando de personalidade real - Getúlio Vargas -, o enredo não é biográfico, devendo antes ser entendido como histórico, já que a proposta pauta-se na Era Vargas, respeitando os fatos incluídos na historiografia oficial do Brasil:

A Era Vargas foi um conjunto das políticas econômicas e sociais que marcaram de maneira indiscutível o processo de industrialização, urbanização e organização da sociedade brasileira. Militares, corporativismo sindical, autoritarismo político e centralização administrativa, nos primeiros anos de governo e na área econômica, o nacionalismo e o intervencionismo, formaram as peças fundamentais da Era Vargas (CENTRO DE MEMóRIA, v.1, 2000, p. 241). 


\begin{tabular}{|c|c|c|c|c|}
\hline \multicolumn{5}{|c|}{ SEGUNDA-FEIRA } \\
\hline Dia & $\begin{array}{l}\text { Escola } \\
\text { Samba }\end{array}$ & Carnavalesco & Enredo & $\mathbf{T}$ \\
\hline S1 & Unidos da Tijuca & Chico Spinosa & $\begin{array}{l}\text { Terra dos papagaios, navegar foi } \\
\text { preciso... }\end{array}$ & A \\
\hline S2 & Mangueira & Alexandre Louzada & $\begin{array}{l}\text { Dom Obá II "Rei dos esfarrapados, } \\
\text { Príncipe do povo" }\end{array}$ & $\mathrm{A} / \mathrm{I}$ \\
\hline S3 & Salgueiro & Mauro Quintaes & $\begin{array}{l}\text { Sou rei, sou Salgueiro, meu reinado é } \\
\text { brasileiro }\end{array}$ & $\mathrm{H}$ \\
\hline S4 & $\begin{array}{l}\text { I m peratriz } \\
\text { Leopoldinense }\end{array}$ & Rosa Magalhães & $\begin{array}{l}\text { Quem descobriu o Brasil, foi seu Ca- } \\
\text { bral, no dia } 22 \text { de abril, dois meses de- } \\
\text { pois do carnaval... }\end{array}$ & $\mathrm{H}$ \\
\hline S5 & $\begin{array}{l}\text { llha do } \\
\text { Governador }\end{array}$ & Mário Borriello & ... Pra não dizer que não falei de flores & A \\
\hline S6 & Beija-Flor & $\begin{array}{l}\text { Comissão de } \\
\text { carnaval }^{3}\end{array}$ & $\begin{array}{l}\text { Brasil - um coração que pulsa forte. } \\
\text { Pátria de todos ou terra de ninguém }\end{array}$ & $\mathrm{H}$ \\
\hline S7 & Viradouro & Joãozinho Trinta & Brasil: visões de paraísos e infernos & A \\
\hline
\end{tabular}

O primeiro enredo da noite de segunda-feira, do carnaval de 2000, chamava-se "Terra dos papagaios, navegar foi preciso...", desenvolvido pelo GRES Unidos da Tijuca baseava-se na imagem paradisíaca do Brasil, na época de seu descobrimento. Por se tratar de um enredo que não tem compromissos com os fatos históricos, o classificamos como associativo, pois a intenção do carnavalesco Chico Spinosa era ressaltar as cores da fauna e flora naquele momento, além de mostrar uma pacífica relação entre os povos (indígenas e portugueses).

A Estação Primeira de Mangueira, com enredo assinado por Oswaldo Martins e tendo como carnavalesco Alexandre Louzada fez uma homenagem a um personagem que transita entre a realidade e a fantasia, na figura de Cândido da Fonseca Galvão, conhecido como Dom Obá II d'África. No histórico do enredo "Dom Obá II 'Rei dos esfarrapados, Príncipe do povo'", há uma afirmação informando que este enredo é ficcional, pois associa passagens verídicas com fatos imaginários. Por isso, classificamos o referido enredo como de associação e, ao mesmo tempo, imaginário.

Optamos por classificar como histórico o enredo "Sou rei, sou Salgueiro, meu reinado é brasileiro", desenvolvido por Mauro Quintaes para o Salgueiro, em 2000. O carnavalesco se utiliza de passagens históricas do Brasil para contar nossa história, a partir da perspectiva de dom João VI e a chegada da corte portuguesa no Brasil, conforme explicitado no histórico do enredo:

Nosso enredo vai mostrar o início do amadurecimento do Brasil, quando passou de Colônia a Reino Unido. Curiosamente, partiu da França a influência que favoreceu essa transformação: primeiro pela força, com Napoleão praticamente expulsando a Corte de 
Portugal; e depois pela arte, com o legado documental da Artística Missão (CENTRO DE MEMóRIA, v.2, 2000, p. 76).

A Imperatriz Leopoldinense, com o enredo "Quem descobriu o Brasil foi seu Cabral, no dia 22 de abril, dois meses depois do carnaval...", desenvolvido por Rosa Magalhães, coloca em relevo as trocas comerciais realizadas entre colonizadores e a colônia. Ademais, esse enredo, que ressalta nossas riquezas naturais, minerais e vegetais, traz em seu título a data de descobrimento do Brasil, um fato histórico que, por si só, o classifica como histórico.

A carnavalesca abre o Histórico do enredo com a seguinte passagem:

Os séculos XV e XVI foram épocas de descobertas. A própria redondeza da terra era objeto de larga e apaixonada indignação dos mais altos espíritos; o astrolábio e outros instrumentos de navegação passaram a ser utilizados de modo amplo. A noção de circularidade abrange a fisiologia, pois descobriu-se que o sangue circula pelo corpo humano, e as notícias circulavam também, como o advento da imprensa (CENTRO DE MEMÓRIA, v.2, 2000, p. 104).

E na Justificativa do enredo a carnavalesca explica que:

Os interesses comerciais, a criação de entrepostos na Índia e na África, o sonho de Dom Manuel em conquistar o monopólio de especiarias tão caras, que davam sabor a alimentos de gosto precário, foi uma espécie de mola propulsora para esses navegantes. Tão caro quanto pimenta, era usado no dia a dia, mostrando que realmente era um comércio valioso. (...) As pedras preciosas, o ouro, o marfim também fazem parte das mercadorias, bem como os escravos, que já eram comercializados e usados pelos portugueses, desde os meados do século XV (1450 aproximadamente) (CENTRO DE MEMÓRIA, v.2, 2000, p. 106).

Mario Borriello desenvolveu o enredo “... Pra não dizer que não falei de flores", em 2000, para o GRES União da Ilha do Governador. Mesmo apresentando uma extensa lista de datas e fatos no histórico do enredo (entre 1964 e 1985), o carnavalesco afirma que não pretende reconstituir uma sequência linear dos fatos, no recorte histórico referente à ditadura militar. Por isso, classificamos este enredo como associativo.

A comissão de carnaval da Beija-Flor desenvolveu o enredo "Brasil um coração que pulsa forte. Pátria de todos ou terra de ninguém" e afirmava a pretensão de recontar a história do Brasil: "A Beija-Flor de Nilópolis no carnaval de 2000 leva para a Avenida muito mais do que um enredo, na verdade vamos recontar a história do Brasil" (CENTRO DE MEMÓRIA, v.2, 2000, p. 164). Entendemos esse enredo como histórico, pois observamos, ainda, que a comissão de carnaval 
fez uma pesquisa que verificou mapas, livros de história e relatos oficiais que pautaram todo o desenvolvimento do enredo de cunho histórico, como afirma a seguinte passagem:

Mapas originais, muito antigos, do começo do século IX, e dos séculos X, XI e XII, conservados no Vaticano e na Galeria Dei Uffize, na Itália, mostram uma Terra Papagalis, uma Ilha do Brasil ou o Novo Mundo, muito para lá do continente africano, no meio do oceano Atlântico (CENTRO DE MEMóRIA, v.2, 2000, p. 165).

A Viradouro levou para a avenida, em 2000, o enredo "Brasil: visões de paraísos e infernos". Nele, Joãosinho Trinta apoiou-se na visão imaginária do europeu medieval, segundo a qual o mundo possuía um Paraíso e um Inferno na Terra. Nesse contexto, o carnavalesco faz associações entre os diversos tipos de paraísos e infernos vividos pela humanidade, ao longo dos tempos. Por isso, classificamos esse enredo como associativo.

\section{CONCLUSÃO}

As palavras finais deste artigo servem mais como um primeiro balanço e reflexão parcial do que já foi pesquisado, do que como conclusão propriamente dita. Como nossa pesquisa ainda se encontra em desenvolvimento, mostramos apenas uma parte do caminho já percorrido.

Pensamos em iluminar um assunto que geralmente só provoca interesse nos dias que antecedem (ou sucedem) as apresentações dos desfiles das escolas de samba. Com esse trabalho, entendemos um pouco mais sobre a dinâmica de criação dos enredos para as escolas de samba, como fios condutores para seus desfiles e, consequentemente, o trabalho desenvolvido na criação de fantasias e alegorias, como os elementos plástico-visuais apreciados pelo público.

Ao longo da pesquisa, percebemos que alguns enredos, mesmo havendo pesquisa histórica para apoiar o desenvolvimento dos temas, nem sempre foram classificados, exclusivamente, como históricos, por exemplo. Às vezes, os fatos históricos são apenas o início do argumento que, posteriormente, segue outra abordagem, configurando enredos imaginários, associativos, de localidade ou, ainda, biográficos. Há, ainda, casos de enredos considerados híbridos, principalmente quando se guiam por duas ou mais abordagens - nesses casos, colocamos sempre uma barra ("/") entre elas.

Nosso critério para identificar os enredos como históricos pautou-se, unicamente, no texto desenvolvido pelas próprias agremiações, seja no Histórico do enredo ou na Justificativa do enredo, ambos descritos nos cadernos AbreAlas. 
A seguir, apresentamos quadro resumindo a pesquisa até aqui desenvolvida (o ano de 2000), separando horizontalmente por ano e verticalmente pela classificação do enredo (H-Histórico; L-Localidade; A-Associação; B-Biográfico; I - Imaginário; e MIX quando o enredo apresenta características híbridas.

\begin{tabular}{|l|l|l|l|l|l|l|r|}
\hline & H & L & B & I & A & MIX & Total \\
\hline Domingo & 4 & - & - & 1 & 3 & -1 & 7 \\
\hline Segunda & 3 & - & - & 1 & 4 & -1 & 7 \\
\hline & 7 & - & - & 2 & 7 & -2 & 14 \\
\hline
\end{tabular}

Dessa maneira, observamos que os enredos considerados históricos são apenas sete, quantidade inferior à que suspeitávamos antes do início da pesquisa, ou seja, em torno de 50\%. Outra observação diz respeito à pesquisa histórica que está presente na maioria dos argumentos, mas que sofre diversas interferências antes de tomar forma nos desfiles da Sapucaí. A outra metade dos enredos classificados integrou os de cunho associativo, perfazendo também o total de sete, tendo em dois casos, a hibridação de associativo e imaginário. Como não estamos levando em consideração os fatos históricos dos enredos associativos, percebemos que há grande quantidade deles porque abarcam maior variedade de assuntos.

Pretendemos apresentar o resultado final dessa pesquisa, em forma de levantamento e análise, em publicações de cunho acadêmico a fim de revelar quais os temas de maior interesse no início desse século (e desse milênio).

Por fim, ambicionamos desenvolver outra pesquisa a partir desse levantamento, do qual só consideraremos os enredos históricos, para analisar as fantasias que tiveram inspiração em fatos históricos. Dessa forma, pretendemos continuar pesquisando sobre o carnaval carioca e, mais especificamente, sobre a dinâmica das escolas de samba cariocas.

\section{REFERÊNCIAS BIBLIOGRÁFICAS}

ARAÚJO, Eugênio. Os temas-enredos das pequenas escolas de samba cariocas. Textos escolhidos de cultura e arte populares. Rio de Janeiro, v.7, n.2, novembro 2010.

BOURDIEU, Pierre. Mercado dos bens simbólicos. In: Economia das trocas simbólicas. São Paulo: Perspectiva, 2009.

CENTRO DE MEMÓRIA DO CARNAVAL. Abre-Alas, 2 v.. Rio de Janeiro: Liesa, 2000.

FARIAS, Júlio César. O enredo de escola de samba. Rio de Janeiro: Litteris, 2007. 
MAGALHÃES, Rosa Lúcia Benedetti. Fazendo carnaval: The making of carnival. Rio de Janeiro: Nova Aguilar, 1997.

OLIVEIRA, Madson Luís Gomes de. Imaginários da criação: o tempo e o espaço dos souvenirs carnavalescos. Rio de Janeiro: PUC-Rio (Tese de doutorado), 2010.

\section{NOTAS}

1 Essa pesquisa decorre de dois principais motivos: o desenvolvimento da tese de doutorado em design/PUC-Rio (defendida em agosto de 2010) e a prática do ensino sobre figurino no curso de Artes Cênicas/UFRJ. Na pesquisa realizada para o doutoramento, entramos em contato com algumas práticas envolvidas na feitura dos desfiles carnavalescos, com o foco principal nos figurinos carnavalescos. Ademais, ministrando aulas para o curso de Artes Cênicas/UFRJ, ratificamos nosso interesse em transmitir novos conhecimentos aos futuros cenógrafos e figurinistas que podem atuar junto aos canais televisivos, teatros, espetáculos e, ainda, nos desfiles de escolas de samba.

2 Segundo Bourdieu (2009, p. 105), "O sistema de produção e circulação de bens simbólicos define-se como o sistema de relações objetivas entre diferentes instâncias definidas pela função que cumprem na divisão do trabalho de produção, de reprodução e de difusão de bens simbólicos. O campo de produção propriamente dito deriva sua estrutura específica da oposição (...), de um lado, o campo de produção erudita (...) e, de outro, o campo da indústria cultural".

3 Composta por Fran-Sérgio, Ubiratan Silva, Cid Carvalho, Nelson Ricardo e Shangai.

Madson Luís Gomes de Oliveira é doutor em design pelo Programa de Pós-Graduação em Design da PUC-Rio e professor do Curso de Artes Cênicas/Cenografia e Indumentária da Escola de Belas Artes da UFRJ.

Recebido em: 15/03/2012

Aceito em: 29/03/2012 